\title{
O sistema de farmacovigilância em Portugal (sua criação e desenvolvimento)
}

\author{
The pharmacovigilance system in Portugal \\ (establishment and development)
}

Ana M. Corrêa-Nunes 1

\author{
1 Instituto Nacional \\ da Farmácia e do \\ Medicamento (Infarmed), \\ Ministério da Saúde \\ Endereço para correspondência: \\ Rua Augusto Pina № 17, \\ 4a Esquina, 1500, \\ Lisboa, Portugal.
}

\begin{abstract}
A bstract The safety profile of a drug is not a static concept. It progresses and can change on the basis of scientific data gathered before and after it is marketed. Therefore, it is now consi dered fundamental that all countries have the capacity to continuously monitor the safety of medicines authorized for sale. Based on the resulting and appropriate data, this allows them to alter the previously authorized conditions for use of a given drug as a public health safeguard. This paper describes how a Pharmacovigilance System is being developed in Portugal in the 1990s. The system is being implemented based on our national characteristics and positions within the European Union. The article includes some results from the initial implementation of these methods. Many similarities allow one to extrapolate some of the procedures from one country to another. When we began we borrowed and adapted extensi vel y from experiences al ready tested by others.
\end{abstract}

Key words Pharmacovigilance; DrugUtilization; Drugs; Portugal

Resumo O perfil de segurança dos medicamentos não é um concei to estático, ele evolui à medida que aumentam os conheci mentos sobre el es coligi dos, antes e após a sua comercialização. Por isso, hoj e se reconhece como fundamental que todos os países possuam a capaci dade de monitorizar de forma contínua a segurança dos fármacos que autorizam. Isso I hes dá a possibilidade de, medi ante os dados que vão col etando, ter o conheci mento necessári o que l hes permita, quando adequado, modificar as condi ções previamente estabel eci das para a uti lização de um medicamento, protegendo assim a saúde pública. Neste artigo, descreve-se como, na década de 90, está a ser construí do um si stema de farmacovigi lância em Portugal. Tendo em conta as características do País e a sua inserção na União Européia, são abordados os programas que estamos a utilizar para a inclusão dos notificadores e o modo como o sistema está a ser desenvolvido. I gual mente são apresentados já al guns resultados desses pri mei ros anos da apl icação desses mé todos. Há muitas semel hanças que permitem extrapolar, de país para país, procedimentos nesta área. Outrossi m, quando começamos, transpusemos e adaptamos muitas das experiências já testadas por outros.

Palavras-chave Farmacovigilância; Uso de Medicamentos; Medicamentos; Portugal 


\section{Introdução}

Ao contrário dos restantes países da Europa Comunitária, até ao início da década de 90 não existia em Portugal qualquer atividade organizada no domínio da farmacovigilância, quer da parte das autoridades de saúde, quer das universidades, exceção, apenas, para alguns representantes da indústria farmacêutica multinacional, que, por razões de política interna, mantinham equipes treinadas nesta área.

Em 1986, tínhamos entrado para a então Comunidade Econômica Européia (CEE), hoje União Européia (UE), onde já havia regras comuns estabelecidas ou em negociação entre os estados membros (EM) para todo o setor dos medicamentos, e esse fato começava a impor grandes mudanças ao nosso país.

O primeiro passo importante foi dado em 1991, quando da publicação do chamado Estatuto do Medicamento (Decreto-Lei 72/91 de 8 de fevereiro) (Figura 1). Ele tornou direito nacional a legislação comunitária já em vigor, estabelecendo as novas normas para os fármacos de uso humano, no que diz respeito às condições de aprovação, comparticipação, controle de qualidade e fabricação.

Aí se fala pela primeira vez em farmacovigilância, estabelecendo que a indústria farmacêutica e os profissionais de saúde deveriam enviar às autoridades de saúde as notificações de reações adversas de medicamentos das quais tivessem conhecimento.

Estavam, desse modo, criadas condições para avançar nesse campo, e precisava-se compensar, de alguma forma, o tempo perdido. Vejamos, pois, como conseguimos evoluir.

\section{Processo de organização}

A base legal que constituía o Decreto-Lei 72/91 permitia-nos iniciar a construção de uma pequena estrutura que possibilitasse, por um lado, dar resposta ao que aquela legislação já estipulava, ou seja, receber as notificações das reações adversas que se pediam, por outro, desenvolvêla, criando assim condições para o cumprimento de futuros normativos legais mais detalhados e completos que seriam, mais tarde, publicados.

No plano nacional, constituíram passos fundamentais a construção da primeira ficha de notificação, o início da admissão e treinamento de pessoal técnico e a elaboração dos programas que mais tarde nos permitissem incluir os notificadores.

No plano internacional, iniciamos todo o trabalho que tornasse possível a nossa aceita- ção futura como membros do programa internacional de monitorização de medicamentos da Organização Mundial de Saúde (OMS).

Isso passou pela adoção de, entre outros, um conjunto de técnicas e regras homologadas pela OMS, bem como pelo controle de qualidade da sua utilização (Edwards \& Biriell, 1994). I gualmente, foi tida em conta a nossa inserção européia e condição de país membro daquela comunidade. Desde o início, estivemos sempre representados no grupo de trabal ho que coordena, na UE, as atividades de farmacovigilância. Assim, todo o crescimento do nosso sistema considerou essa realidade e foi sendo desenhado a fim de permitir uma boa articulação com os outros estados membros.

Em farmacovigilância, a troca de informação é fundamental, sobretudo quando se trata de países onde os dados nessa área são escassos, ou porque estão no início dos sistemas, ou porque são de pequena dimensão. No nosso caso, estão presentes os dois aspectos e essa boa articulação desde cedo, com a OMS e a UE, era fundamental.

\section{Enquadramento legal}

A partir do meio do ano de 1992, tínhamos já condições para começar a divulgar o sistema aos futuros notificadores: médicos das carreiras de clínica geral e hospitalar, farmacêuticos e indústria farmacêutica. Para isso, fez-se sair o Despacho Normativo 107/92 de 27 de junho (Figura 1), que criou oficialmente um Sistema Nacional de Farmacovigilância (SNF) apoiado, nos aspectos técnicos, por uma Comissão de peritos, sendo aí também estabelecido o âmbito das suas funções.

Mais tarde, em 1993, já com uma estrutura incipiente a dar os primei ros passos, é publicado o Decreto-Lei 353/ 93 de 7 de outubro (Figura 1). Esse documento legal faz nascer o Instituto Nacional da Farmácia e do Medicamento (Infarmed), organismo central do Ministério da Saúde, que vai reunir todas as funções, até aí dispersas ou inexistentes, da área do medicamento. Com o nível de uma Direção de Serviços desse instituto, é nele criado o Centro Nacional de Farmacovigilância (CNF) (Figura 2), com a atribuição de continuar a implementação do sistema já em marcha.

Estava assim completo o enquadramento legal necessário ao suporte das atividades nessa área, as quais, sem esse forte compromisso governamental, seria difícil de fazer vingar e progredir. 
Figura 1

Seqüência dos documentos legais de suporte à existência de farmacovigilância em Portugal.

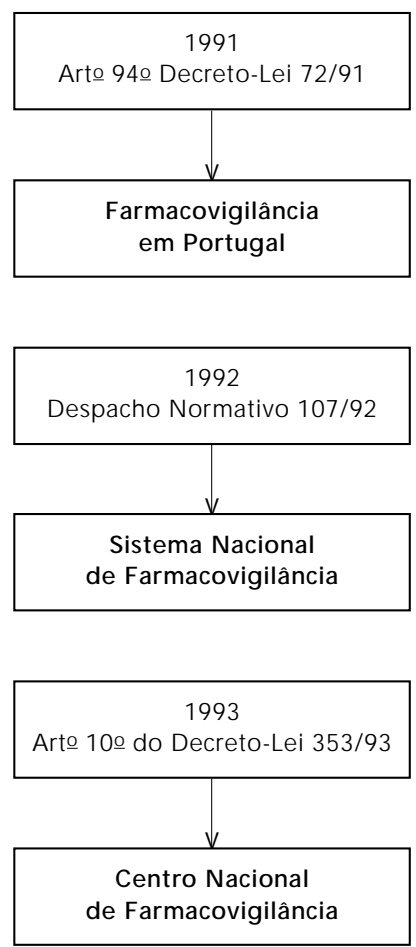

Programas de inclusão dos notificadores

Ao desenhar esses programas, levamos em consideração as características de Portugal em determinados aspectos que consideramos relevantes:

- Trata-se de um país com fraca tradição no domínio da farmacologia clínica e onde toda a investigação relativa a medicamentos estava muito incipiente. Tal fato, de al gum modo, explica-se pelo pouco peso dado pelas universidades a toda essa temática, estando, também, relacionado com a quase inexistência de investigação inovadora na indústria farmacêutica nacional. Por essas razões, e de um modo geral, a formação e práticas nesse campo, por parte dos profissionais de saúde, eram limitadas e essa dificuldade tornava-se crucial, uma vez que esse sistema depende fundamentalmente da atividade dos notificadores como tal.

- Por outro lado, beneficiávamo-nos do fato de Portugal ser pequeno em área geográfica, ter somente dez milhões de habitantes, com apenas trinta mil médicos e cerca de seis mil farmacêuticos. A nosso favor, vinha ainda a forte influência que neste setor exercia a adesão à EU, além do fato de aí termos como parceiros países com fortes tradições nessa área e com procedimentos já bem testados, com os quais muito podíamos aprender.

Decidiu-se, então, separar os notificadores em grupos, com esquemas de integração adaptados a cada um deles, considerando-se as realidades muito diferentes em que exercem a sua atividade (Edlavitch, 1988).

Dentro das carreiras médicas, individualizamos as de clínica geral e a hospitalar, que, em conjunto, detêm praticamente os $100 \%$ da prescrição nacional. Relativamente aos farmacêuticos, separamos os de oficina (farmácia comunitária), dos hospitalares. A indústria farmacêutica nacional e as representantes das multinacionais foram integradas, constituindo um só grupo. Os outros profissionais de saúde com interesse, por também lidarem com medicamentos, eram abordados no programa mais adequado, daqueles grupos já separados, como as enfermeiras e os técnicos de raio- $x$, os quais seriam englobados no programa dos hospitais.

\section{Especificando agora cada programa}

Iniciamos pelos médicos de clínica geral, carreira que compreende cerca de 8.500 médicos e detém cerca de $80 \%$ do total das prescrições. Esses profissionais atuam nos centros de saúde distribuídos por todo o território e, ao contrário do que ocorre nos hospitais, onde se exerce uma medicina em equipe, os clínicos gerais trabalham isoladamente, o que teve de ser levado em consideração.

Assim, fizemos com que o treinamento de tais profissionais se desse de uma forma sistemática, objetivando uma cobertura total. Baseamo-nos, para isso, na sua estrutura organizativa por regiões, obtendo o apoio dos seus superiores hierárquicos e deslocando o pessoal já treinado no Centro Nacional. Foram feitas reuniões informais de debate, em pequenos grupos, por todo o País, as quais tiveram como propósito um bom esclarecimento sobre esse assunto (Corrêa-Nunes \& Carmona, 1993). Questões como: o que é, para que serve e como se faz farmacovigilância; o que se vai notificar, como se procede à coleta de dados em nível nacional, qual o tratamento e destino posterior do material enviado ao Centro, eram exaustivamente debatidas (Corrêa-Nunes, 1992; Corrêa-Nunes \& Carmona, 1993). I gualmente, toda a utilização da ficha, o seu modo de preenchimento, os dados indispensáveis, o envio com porte pago etc., eram também abordados. Deu- 
Figura 2

O rganograma do Instituto Nacional da Farmácia e do Medicamento (Infarmed) de acordo com o Decreto-Lei $353 / 93$.

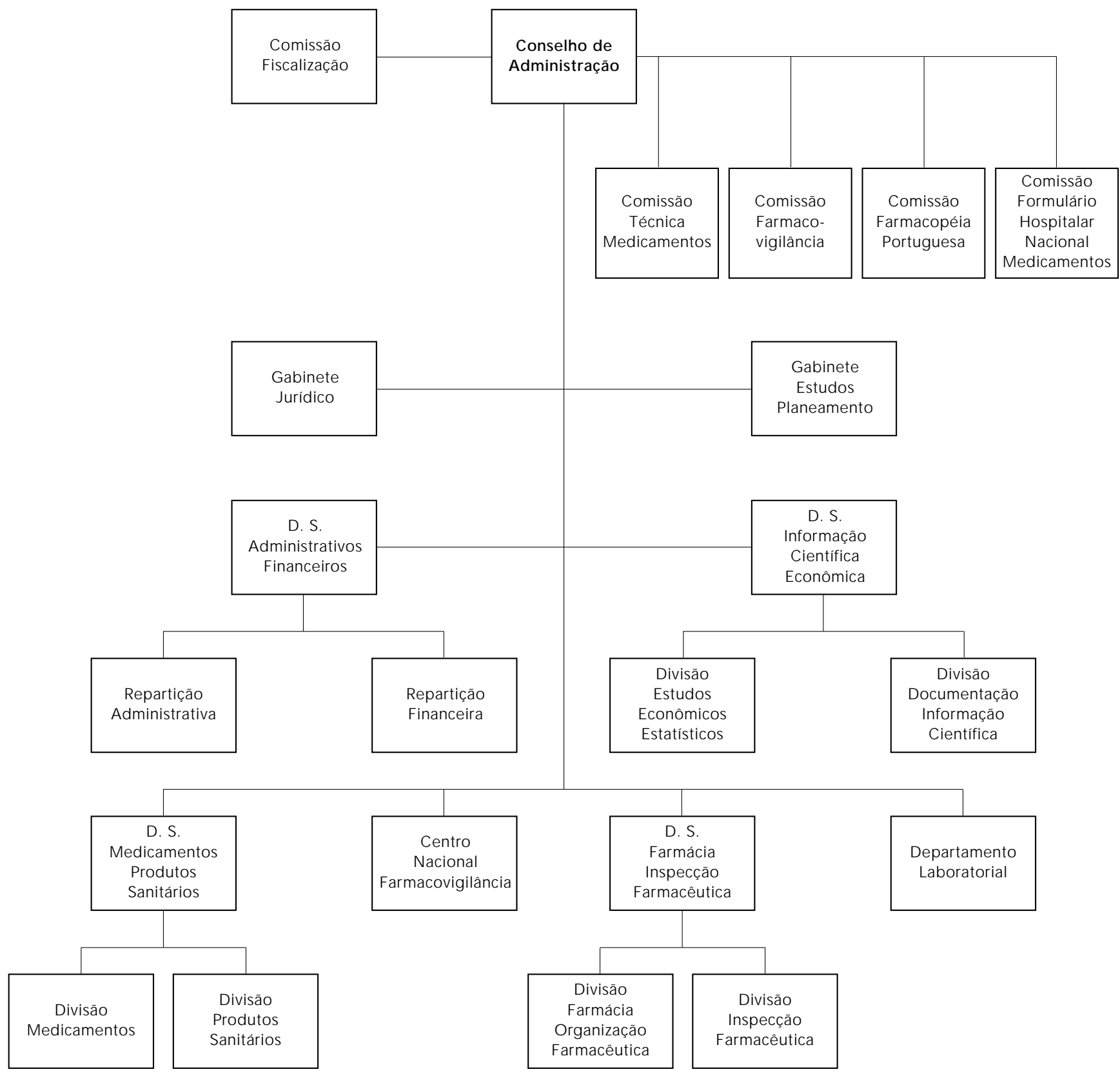


-se grande importância à explicação sobre o re torno da informação após o tratamento das notificações, em carta resposta individual. Divulgou-se também o apoio fornecido pelo Centro em consulta telefônica ou outra, sobre problemas relativos à segurança na utilização de medicamentos, pesquisas bibliográficas com envio de documentação, entre outros esclarecimentos.

Toda a ação decorria com o espírito do estabelecimento de uma parceria, entre o Centro e os prescritores, com a finalidade de ajuda mútua, visando melhorar a segurança dos medicamentos a utilizar (Corrêa-Nunes, 1992; CorrêaNunes \& Carmona, 1993). Só no final era distribuído o material, constituído pelas fichas e umas instruções simples de preenchimento. Consideramos sempre de grande importância o fato de não enviar ou distribuir material sem antes dar as devidas orientações.

Esse treinamento intensivo, que durou mais de um ano, foi acompanhado de artigos na imprensa médica e leiga, com o intuito de reforçar a nossa mensagem e conseguir o início rápido da notificação. Mais tarde, quando essa primeira etapa estava completa e nos dirigimos para os outros grupos, tentamos não deixar de aparecer completamente, não só continuando a utilizar a imprensa especializada ou outra, como fazendo comunicações sobre diversos temas de farmacovigilância, em congressos ou outras reuniões mais amplas, dirigidas aos clínicos gerais.

Estávamos já no final do ano de 1993, quando começamos o envolvimento do grupo seguinte, que foi a indústria farmacêutica. O trabalho aqui estava muito facilitado, pois, na sua grande maioria, as empresas estavam já organizadas ou em processo de organização para colaborar com o Sistema. Apenas tivemos que elaborar as normas escritas, com o detalhe necessário, ao bom cumprimento do que a legislação impunha.

Como conseqüência da nossa participação, desde o início, no grupo europeu de farmacovigilância, essas normas já refletiam grande parte dos procedimentos que mais tarde seriam adotados no nível da União Européia e para os quais toda a indústria já se preparava. Da mesma forma, sempre que possível foram seguidos modelos internacionais anteriormente utilizados pela indústria, como os dos grupos Cioms I (Cioms, 1990) ell (Cioms, 1992).

Durante o trabalho de elaboração de tais normas, houve um acompanhamento dos representantes da indústria, mediante suas associações, chamados a discutir os projetos intermediários. Outrossim, após a publicação do documento final, houve ampla troca de informação em reuniões de debate com o pessoal do Centro Nacional. Entretanto, com a Ordem dos Farmacêuticos e a Associação Nacional de Farmácias, foi formado um grupo de trabalho para elaborar um programa que integrasse os farmacêuticos de oficina no Sistema (Freire \& Corrêa-Nunes, 1994; Corrêa-Nunes \& Lima, 1995).

O fácil acesso dos doentes à farmácia, a orientação exclusiva do farmacêutico para a área do medicamento e a cobertura da faixa da venda sem receita médica são algumas das razões de peso para que estes profissionais de saúde sejam muito úteis a estes sistemas (Freire \& Corrêa-Nunes, 1994; Corrêa-Nunes \& Lima, 1995; Roberts et al., 1994).

Alguns problemas, no entanto, dificultam esse processo e têm justificado que, em alguns países, os farmacêuticos não estejam integrados (Roberts et al., 1994). O motivo fundamental deve-se ao fato de a reação adversa pressupor um diagnóstico cuja precisão é fundamental a todo o processo, e o curriculum do farmacêutico não o habilitar a tal. Vários programas têm sido experimentados para tentar resolver este problema, sem grande sucesso. Desse modo, e ao contrário do que ocorre em outros casos em que podemos socorrer-nos da experiência de outros países mais avançados nessa área, aqui tivemos que criar a nossa própria alternativa que está ainda em regime experimental.

Esse programa implica uma estreita colaboração entre o farmacêutico e o médico, para que este último faça a validação clínica da descrição do efeito suspeito relatado pelo farmacêutico. Para isso, foi adaptada uma ficha própria, tendo como base a dos médicos, diferindo na cor, no fato de ser em três vias, numerada, e ter um conteúdo um pouco diferente. Após o seu preenchimento, o original é enviado ao médico responsável pelo doente ou pela prescrição, uma cópia segue para o Centro Nacional e outra fica retida pelo farmacêutico para seu controle. O médico, ao receber esta notificação, faz a descrição clínica do caso na ficha que usa habitualmente, juntando os detalhes por ele considerados necessários ao tratamento daquele caso e envia ao Centro Nacional, mencionando o número de identificação da ficha do farmacêutico que desencadeou o processo. A informação reunida no Centro é considerada; desse modo, sempre existe a possibilidade de voltar-se a contatar o médico ou o farmacêutico durante o processo de validação (Corrêa-Nunes \& Lima, 1995).

Tal como para os outros programas, também aqui se está a preceder à integração dos 
notificadores, com reuniões de explicação e debate sobre o que é, para que serve e como funciona o Sistema.

A particularidade dessas reuniões, onde estão os farmacêuticos que trabal ham nas farmácias, é que também fazemos estar presentes um número significativo de médicos de clínica geral dos centros de saúde da zona a que as farmácias pertencem. Além de esse fato constituir mais uma oportunidade de Ihes fal ar do Sistema, serve também para estabelecer o primeiro passo para o futuro trabalho em equipe, uma vez que serão estes clínicos os principais receptores das notificações enviadas por estes farmacêuticos.

Também aqui estas ações estão sendo acompanhadas de artigos publicados sobre o mesmo assunto, na imprensa que lhes é dirigida ou por meio de comunicações em congressos e em outras reuniões científicas da área.

Esse programa está para ser iniciado, não tendo ainda sido feita uma cobertura total do País, não sendo possível, por enquanto, concluir sobre a sua eficácia.

Os médicos e farmacêuticos hospitalares estão igualmente a ser aos poucos integrados.

Atingir este universo é vital para avaliar a segurança dos medicamentos, basta pensar que grande parte das reações adversas graves passam pelos hospitais. Estatísticas internacionais apontam para 3\% a 7\% o número de admissões em serviços de urgência que têm como causa fármacos, estes motivando $10 \%$ a $20 \%$ dos internamentos (Johnston et al., 1990); em outros trabal hos mais recentes, as percentagens são ainda maiores (Classen et al., 1997).

É, no entanto, constante, em todos os países, uma grande dificuldade na implementação de uma boa rede de notificação hospitalar. Isto é independente do desenvolvimento científico ou da tradição em farmacovigilância do país em causa. A subnotificação elevada neste setor está ligada, entre outros, às características particulares da prestação de cuidados de saúde nessas instituições.

As várias estratégias estudadas para superar este problema, de importância fundamental nesta ciência, passam por um ponto comum: o papel do farmacêutico hospitalar (Roberts et al., 1994). Nos vários programas já implementados com sucesso, verifica-se um aumento dos níveis de notificação na ordem dos $50 \%$ e mais, quando aos farmacêuticos foi dado papel relevante (Roberts et al., 1994).

Tendo isto em conta, as ações que neste campo temos levado a cabo englobam sempre médicos e farmacêuticos em conjunto. O papel de cada um é tratado como complementar e em equipe. Ao farmacêutico são dados, sempre que possível, instrumentos que facilitem a ligação com o médico, como, por exemplo, posicionar a farmácia hospitalar como base privilegiada de ligação com o Centro Nacional, não só para o envio de reações adversas notificadas no hospital, mas também como receptor da informação de segurança que o Centro necessite fazer chegar ao hospital. Por outro lado, o trabaIho do farmacêutico junto do médico fundamenta-se em pontos-chave:

- O farmacêutico deverá constituir uma boa ligação com o médico.

- O farmacêutico deve recorrer a várias técnicas para uma procura sistemática de sinais indiretos de reações adversas, sobre os quais posteriormente irá discutir com o médico, resultando disso a identificação dos casos suspeitos a notificar em conjunto. São hoje várias as técnicas utilizadas nessa pesquisa, que exemplificamos com a atenção especial às requisições à farmácia de antídotos ou tracer drugs (medicamentos de pista ou receituário de alerta), ou com o estudo dos casos em que os resultados da monitorização sérica de medicamentos feita pelo farmacêutico aponta para casos suspeitos, ou ainda com o seguimento dos casos após testes específicos, como as pesquisas de Clostridium difficile (da colite pseudomembranosa) etc.

Tudo isso está sendo amplamente discutido com esses profissionais, aos poucos por todo o País, fazendo-se uso, também, da imprensa que Ihes é dirigida, de congressos ou de outras reuniões. Como a medicina hospitalar é uma prática de equipe, os responsáveis pelos serviços são os principais alvos para veicular a transmissão dessa mensagem aos médicos, responsabilizando-os pela implementação do hábito de pesquisa e notificação das reações adversas, dentro dos grupos de que são os responsáveis.

Tal como acontece com os farmacêuticos de oficina, também o programa dos hospitais não pode ainda ser avaliado, tendo em conta o curto tempo da sua divulgação e o reduzido número das equipes já envolvidas.

\section{Evolução e situação atual}

Com base no que se disse até agora, deduz-se que a tônica dada ao início da nossa atividade situou-se na expansão do sistema em nível nacional. Com esse propósito, decidiu-se concentrar esforços na carreira médica de clínica geral. Razões de várias ordens assim o determinaram, tais como al guma facilidade de rápida 
e massivamente abordar esse grupo, a relativa simplicidade e autonomia do seu funcionamento, o seu enorme poder de prescrição (80\% do total nacional), a maior facilidade na avaliação dos dados aqui recolhidos por resultarem de esquemas terapêuticos mais simples, havendo ainda toda a informação resultante de um acompanhamento prolongado de cada utente.

Pouco a pouco, essa atividade foi-se repartindo com outra de ordem interna, no Centro Nacional, que progressivamente foi crescendo. Começamos a receber notificações que era necessário tratar e responder, perguntas e pedidos de apoio nesta área que iam aumentando. Também dentro do Infarmed, essa nossa atividade crescente implicou estreitamento de ligações com os outros departamentos, tendo em vista a circulação de informação importante sobre segurança.

Em nível internacional, a nossa ligação com a União Européia acarretava a participação ativa na circulação de informação de segurança entre estados membros, sendo necessário estudar, tratar e discutir em conjunto. Depois, quando justificado, esse procedimento pode implicar, dentro do país, a alteração das condições de utilização dos princípios ativos onde foram demonstrados problemas, com o aviso posterior aos usuários. Essa prática, que também organizamos, é fundamental e consiste em fazer chegar aos profissionais de saúde, através de carta circular, a descrição das alterações feitas quanto à utilização da substância(s) ativa(s) em causa e as razões que a isso levaram.

Essas são as razões que determinaram uma desaceleração na velocidade de inclusão dos dois últimos grupos (farmacêuticos de oficina e hospitais), que ainda decorre.

A evolução do número de notificações é apresentado na Figura 3 e na Tabela 1 . Relativamente à origem das notificações (Tabela 1), é curioso o decréscimo das notificações dos médicos coincidindo com a elevação das da indústria. A investigação desse fenômeno revelou que a indústria, ao ter conhecimento pelo médico da suspeita de uma reação adversa, fazia a sua notificação ao Centro, e o médico, ao saber disso, considerava não ser necessário de sua parte procedimento semelhante. É evidente que essa atitude, conhecida e já descrita por outros (Edlavitch, 1988), teve que ser rapidamente alterada, demonstrando-se aos dois grupos que são independentes e como tal, por questões de segurança, terão que atuar separadamente. O risco de duplicação de notificações é convenientemente acautelado atualmente, por mecanismos e técnicas diversas existentes em todos os Centros Nacionais.

\section{Figura 3}

Evolução do número de notificações/ano.

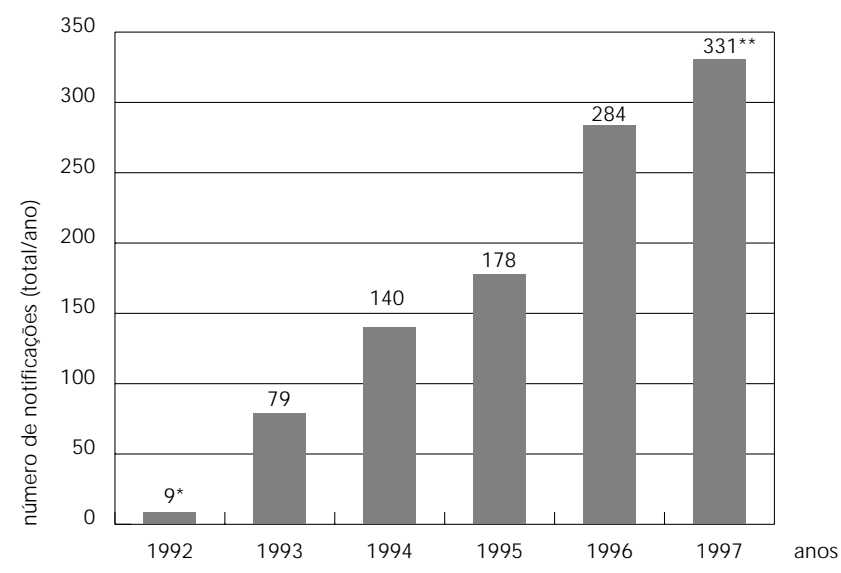

* 3 últimos meses de 1992

** Dados até 30/09/97.

Outros projetos estão ainda hoje no início, como, por exemplo, um boletim do Centro, que irá veicular notícias sobre a segurança que interessem aos usuários dos medicamentos e constituem impactos periódicos sobre este assunto.

Todas essas atividades consomem muito tempo de trabal ho técnico, e a velocidade de admissão e treinamento do pessoal necessário é por vezes lenta. Isso impõe um ritmo sempre mais lento do que o desejável, sendo preciso a cada momento nova análise do processo de crescimento, reavaliando as prioridades.

\section{Conclusões}

Consideramos como fatores determinantes para o início e desenvolvimento da farmacovigilância em Portugal a entrada deste País para a União Européia, bem como o forte empenho governamental nesta área, expresso num conjunto de legislação que destaca como relevante a monitorização da segurança dos medicamentos já autorizados, criando condições que asseguram o suporte logístico necessário ao seu progresso.

Importava aproveitar da melhor forma esse contexto favorável com a consciência de que se começava do zero, num país sem tradição na área da farmacologia clínica, onde os notificadores potenciais, de quem ia depender totalmente o sucesso do sistema, desconheciam 
Tabela 1

O rigem das notificações recebidas.

\begin{tabular}{|c|c|c|c|c|c|c|}
\hline & \multicolumn{6}{|c|}{ Notificações/ano (por origem) } \\
\hline & $1992 *$ & 1993 & 1994 & 1995 & 1996 & $1997 * * * *$ \\
\hline Médicos\#\# & $9 *$ & 62 & 67 & 28 & 49 & $160 \#$ \\
\hline Farmacêuticos (oficina) & & & & $3^{* *}$ & $1 * *$ & 3 \\
\hline Indústria & & 8 & 33 & 70 & 47 & 47 \\
\hline Ensaios clínicos*** & & 9 & 40 & 80 & 188 & 127 \\
\hline Total & 9 & 79 & 140 & 178 & 284 & \\
\hline
\end{tabular}

* Só os 3 últimos meses do ano (todas de clínicos gerais).

** N otificações validadas pelos médicos e contabilizadas nas notificações desses médicos.

*** As notificações dos ensaios clínicos vêm todas através da Indústria.

**** Dados até 30/09/97.

\# Metade destas notificações foram devidas a um problema de qualidade com vacinas.

\#\# Só a partir de finais de 1994 começa a haver notificações de médicos hospitalares e ainda são exclusivamente de Dermatologistas que voluntariamente pediram para aderir ao sistema.

mesmo, na sua maioria, o seu significado. A necessidade de recrutar e treinar todo o pessoal técnico constituiu outra dificuldade a ser considerada. Tínhamos, por outro lado, a necessidade premente de ganhar um tempo perdido de quase trinta anos de evolução nessa área, que nos separavam da maioria dos países nossos parceiros da União Européia, com os quais iríamos, doravante, trabalhar.

Nesse contexto, impunha-se avançar com programas de treinamento cuidados, destinados a vencer tão rápido quanto possível a inércia que tal conjuntura favorecia. Foi dada grande importância ao estudo e planejamento das ações mais adequadas, tendo em conta as características dos diversos destinatários com os interesses e os objetivos do sistema. Resultaram, assim, programas tal hados "sob medida" (Edlavitch, 1988) para os diferentes grupos identificados. Consideramos sempre muito importante o envolvimento, desde o princípio, dos representantes dos grupos de destinatários no planejamento das ações, para melhorar a sua elaboração e ajudar na sua implementação.

Desde o início dos nossos contatos com os notificadores, era dado relevo ao estabelecimento de uma parceria que implicava o imediato apoio do Centro Nacional no forneci- mento de dados ou respostas a questões sobre a segurança de medicamentos, complementado mais tarde com a resposta personalizada às notificações recebidas, cartas circulares sempre que houvesse alterações das condições de utilização de medicamentos, boletim com notícias do Centro etc. Em suma, o sistema não vinha 'pedir mais trabal ho' sem retorno, mas sim, e sobretudo, o trabalho de notificar era mínimo, se comparado com o apoio que a existência do Sistema ia dar (Corrêa-Nunes, 1992; Corrêa-Nunes \& Carmona, 1993). O fato de essa mensagem ser transmitida implicava a existência de meios para a cumprir, sob pena de tudo falhar

O reforço da mensagem inicial com impactos sucessivos foi também contemplado (Edlavitch, 1988).

Por tudo o que foi exposto até então, o planejamento da nossa atividade com um escalonamento de prioridades conforme a disponibilidade previsível da capacidade de resposta do Centro foi muito importante. Isso motivou uma desaceleração progressiva de certas atividades, como a inclusão dos últimos grupos, o que ainda decorre, para poder fazer face aos outros compromissos assumidos, enquanto se vai aguardando aumento da capacidade interna, mais lenta.

\section{Nota dos editores}

Em acordo com a autora, o conselho editorial de Cadernos de Saúde Pública adaptou para o padrão brasileiro algumas expressões encontradas no texto, efetuando também padronização segundo norma ortográfica da língua portuguesa vigente no Brasil. 


\section{Referências}

CLASSEN, D. C.; PESTOTNIK, S. L.; EVANS, R. S.; LLOYD, J. F. \& BURKE, J. P., 1997. Adverse drug events in hospitalized patients-excess length of stay, extra costs and attributable mortality. JAMA, 277:301-306.

CIOMS (Council for International Organizations of Medical Sciences), 1990. International Reporting of Adverse Drug Reactions. Genebra: CIOMSWHO.

CIOMS (Council for International Organizations of Medical Sciences), 1992. International Reporting of Periodic Drug Safety Update Summaries. Genebra: CIOMS-WHO.

CORRÊA-NUNES, A. M., 1992. A importância da farmacovigilância na otimização da terapêutica. Arquivos de Medicina, 5:197-199.

CORREAA-NUNES, A. M. \& CARM ONA, R., 1993. Farmacovigilância - segurança na terapêutica. Saúde em Números, 8:21-23.
FREIRE, C. \& CORRÊA-NUNES, A. M., 1994. Farmacovigilância em Portugal. Revista da Ordem dos Farmacêuticos, 1:20-22.

CORRÊA-NUNES, A. M. \& LIMA, A., 1995. Farmacovigilância em Portugal - o papel do farmacêutico de oficina. Revista da Ordem dos Farmacêuticos, 2:21-25.

EDLAVITCH, S. A., 1988. Adverse drug event reporting, improving the low U.S. reporting rates. Archives of Internal Medicine, 148:1.499-1.503.

EDWARDS, I. R. \& BIRIELL, C., 1994. Harmonization in pharmacovigilance. Drug Safety, 10:93-102.

JOHNSTON, P. E.; MORROW, J. D. \& BRANCH, R. A., 1990. Use of a database computer program to identify trends in reporting of adverse drug reactions. American Journal of Hospital Pharmacy, 47:1.321-1.327.

ROBERTS, P. I.; WOLFSON, D. J. \& BOOTH, T. G., 1994. The role of pharmacists in adverse drug reaction reporting. Drug Safety, 11:7-11. 